University of Nebraska - Lincoln

DigitalCommons@University of Nebraska - Lincoln

$5-2005$

\title{
The Tale of Two Cultures: Attitudes towards Affirmative Action in the United States and India
}

Gwendolyn Combs

University of Nebraska - Lincoln, gcombs2@unl.edu

Sucheta Nadkarni

University of Nebraska-Lincoln, snadkarn@unlnotes.unl.edu

Follow this and additional works at: https://digitalcommons.unl.edu/managementfacpub

Part of the Management Sciences and Quantitative Methods Commons

Combs, Gwendolyn and Nadkarni, Sucheta, "The Tale of Two Cultures: Attitudes towards Affirmative Action in the United States and India" (2005). Management Department Faculty Publications. 51.

https://digitalcommons.unl.edu/managementfacpub/51

This Article is brought to you for free and open access by the Management Department at DigitalCommons@University of Nebraska - Lincoln. It has been accepted for inclusion in Management Department Faculty Publications by an authorized administrator of DigitalCommons@University of Nebraska - Lincoln. 
Published in Journal of World Business 40:2 (May 2005), pp. 158-171; doi: 10.1016/j.jwb.2005.02.002

Copyright (c) 2005 Elsevier Inc. Used by permission.

Published online March 9, 2005.

\title{
The Tale of Two Cultures: Attitudes towards Affirmative Action in the United States and India
}

\author{
Gwendolyn M. Combs and Sucheta Nadkarni \\ Department of Management, University of Nebraska-Lincoln, Lincoln, NE, USA \\ Corresponding author - G. Combs, e-mail gcombs2@unl.edu
}

\begin{abstract}
This study seeks to inform multinational corporations as they integrate domestic and international affirmative action policies and strategies. Improvement of these abilities can have important implications for human resource management and organizational productivity outcomes. To increase our understanding of the international perspectives of affirmative action, we examine employee perceptions of the structure of affirmative action plans in the United States and India. The differences in affirmative action plans implemented in these countries as well as country cultural differences offer interesting backdrops for examining cross-country differences in employee perceptions of affirmative action.
\end{abstract}

A multinational corporation's (MNC) ability to manage diversity and understand cultural differences is critical to its success. Recently, several leading Fortune 500 companies such as Microsoft, Lucent, 3M, General Mills, Dow Chemical Company and Eastman Kodak, expressed their strong support for affirmative action policies. Launching diversity initiatives influences the firm's ability to improve operational and managerial effectiveness across cultures by helping them better adapt to diverse domestic and global markets (Evans, Pucik, \& Barsoux, 2002). This improved cultural ability promotes international trade, knowledge sharing and improved competitive advantage in a global market place (Evan et al., 2002; Iles \& Hayers, 1997). James
Hackett, CEO of Michigan-based Steelcase one of the world largest designers and manufacturers of office products, said "Steelcase's success as a global company is dependent on our ability to hire people who have experience in and are knowledgeable about working in a diverse environment, with diverse ideas, and with people from all walks of life." To effectively manage diversity, MNCs need to integrate domestic policies and initiatives with corresponding practices of the global community (Iles \& Hayers, 1997). Such integration needs consideration of differences in the constitutional, legal and cultural factors affecting management of diversity. A critical issue in ensuring a diverse workforce is setting up affirmative action plans (AAPs). 
Affirmative action as a management tool fosters diversity and opens opportunities for effectively using a diverse pool of individual and collective talents (Crosby \& VanDeVeer, 2000). Setting up AAPs is especially challenging in the global environment. Jain, Stone, and Horwitz (2003) assert that policies designed to address unfair discrimination in MNCs must be mindful of the degree of convergence and divergence of implementation strategies. While the basic premises of the inclusionary policies may be conceptually similar, implementation procedures may vastly differ. Thus, the effective management of AAPs are mediated quite strongly by the national and local context. Factors such as constitutional and legal frameworks, labor market attributes, and historical relations between ethnic and other groups are key factors that may enhance or inhibit effective affirmative action (Jain et al., 2003).

While firms in the United States grapple with assessing the appropriateness of AAPs and employee reactions to various implementations of AAPs, little mention is made of the experiences of firms in other countries in their efforts to foster equal access to employment and educational opportunities. Calling upon the experiences of firms in countries such as India, Malaysia, Canada, Germany, France, Brazil, and South Africa may greatly inform understanding and selecting effective solutions in American firms. To understand affirmative action from an international perspective, we examine the employee perceptions of AAPs in the United States and India.

Our rationale for comparing AAPs in the United States and India is threefold. First, India is emerging as an important part of product innovation and customer service delivery systems for American firms. A recent Business Week (12/8/2003) story showed India's significant participation in major United States industry sectors including software applications development, information technology consulting and network management, customer service call centers, research and development for microprocessors and multimedia chips, and industrial and medical engineering. Second, India has a rich history and experience of dealing with inclusionary policies that are very structured and direct in their prescriptions for affirmative action that was provided in the constitution adopted in 1949. While the United States has not had as long of a history of dealing with af- firmative action, its experience with implementation has been hotly debated since its beginning (Jain et al., 2003).

Finally, the cultural orientations of the two countries offer interesting backdrops for examining differences in employee perceptions of affirmative action in these countries. Studies suggest that differences in cultural beliefs including morals, customs and habits between countries have major implications for the perceptions of and reactions to affirmative action (Ozawa, Crosby, \& Crosby, 1996). India's mandatory affirmative action quotas operating within a collectivist and pluralistic orientation are a stark contrast to affirmative action goals and timetables in an individualistic and non-pluralistic oriented United States. As an exploratory step, this study offers preliminary investigation of cross-country attitudes towards AAPs that may inform MNCs as they integrate domestic and international affirmative action policies and strategies.

\section{Affirmative action in the United States and India}

While improved employment opportunities have been afforded to groups targeted by AAPs in both of the countries, there is evidence that AAPs are still needed because caste-, race- and gender-based discrimination remains a pervasive problem and true inclusiveness and representation for these groups have not been realized (Boston \& Nair-Reichert, 2003; Crosby \& VanDeVeer, 2000; Guerrero, 2002; Turner, 1990). Both countries recognize the persistent and detrimental effects of historically sanctioned laws and practices that result in present day inequities and discrimination. In United States, Justice Ginsburg made such an observation in her dissent in Gratz v. Bollinger (Gratz v. Bollinger, 123 S. Ct. 2411, at 2443, 2003, Ginsburg dissenting):

Unemployment, poverty, and access to health care vary disproportionately by race. ... Adult African American and Hispanics generally earn less than whites with equivalent levels of education. Equally credentialed job applicants receive different receptions depending on their race. Irrational prejudice is still encountered in real estate markets and consumer transactions. Bias both conscious and unconscious, reflecting tradi- 
tional and unexamined habits of thought, keeps up barriers that must come down if equal opportunity and non-discrimination are ever genuinely to become this country's law and practice.

Similarly, in India affirmative action seeks to remedy the effects of a 3000-year-old rigid hierarchal caste system of power, privilege and socio-economic status. The policy with its quotas for underprivileged classes and castes attempts to provide equal opportunity and to recognize past and present injustices that impact the social and economic well-being of Indians. Affirmative action implementation procedures in India suggest that merit is a necessary but not sufficient criterion to address historical injustices (Boston \& Nair-Reichert, 2003).

Table 1 summarizes the various aspects of affirmative action as conceptualized in the United States and India. Outlined are the social/economic/political bases for affirmative action; country approaches to affirmative action; levels of government involvement; focal challenges/resistance to the plan; and the legal impetus for affirmative action (Jain et al., 2003).

In the United States, affirmative action, in pure terms, is based on the removal of employment imbalances for specific racial, ethnic and gender groups (Guerrero, 2002; Nacoste, 1987). These groups are African American, Hispanic Americans, Asian Americans, Native Americans and women. While AAPs are required for government contractors (public and private), the adoption of affirmative action programs is voluntary for most other organizations (Kravitz, 1995; Nacoste, 1987). The prescribed structure of AAPs involves a system of goals and timetables with specific identification of problem areas. The actual implementation plans for affirmative action have primarily been clarified and delineated through a system of court actions and conciliation by the Equal Opportunity Commission (EOC). The EOC is the federal agency responsible for assuring equal employment opportunity for all workers (Crosby \& VanDeVeer, 2000). The monitoring of employer programs can come from federal requirements of contractor or through the specific recommendations of the courts and the EOC when AAPs are prescribed as a remedy for demonstrated past discrimination.

Compared to the United States, the implementation of affirmative action in India is quite different. Affirmative action policy in India is a system of quotas and reservations (Boston \& Nair-Reichert, 2003; Jain et al., 2003). Reservations and quotas require numerical designations for each of the disadvantaged groups considered to have low access to employment and education. These groups are Scheduled Castes (SC), Scheduled Tribes (ST), and Other Backward Classes (OBC). These quotas are codified in the country constitution for what are termed as the socially and economically depressed classes (Jain et al., 2003). The Mandal Commission in 1980 identified the total reservations for Scheduled Tribes, Scheduled Castes and Other Backward Classes as $22.5 \%$ and $27 \%$, respectively (Boston \& NairReichert, 2003; Jain et al., 2003).

Table 1. Summary of affirmative action provisions in the United States and India

\begin{tabular}{|c|c|c|}
\hline Provision & India & United States \\
\hline Approaches & $\begin{array}{l}\text { Removal of employment and educational imbalance } \\
\text { through strict quotas and reservation system }\end{array}$ & $\begin{array}{l}\text { Removal of employment and educational } \\
\text { imbalance through required and voluntary } \\
\text { practices of goals and timetables }\end{array}$ \\
\hline Legal impetus & $\begin{array}{l}\text { Constitution - Articles 14-17; } \\
\text { Mandal Commission; } \\
\text { clarifying court decisions }\end{array}$ & $\begin{array}{l}\text { Fourteenth Amendment Executive Orders } \\
\text { 10925, 11246, } 11375 \text { and 11458; remedial } \\
\text { action under The Civil Rights Act 1964; } \\
\text { OFCCP Revised Order 4; various } \\
\text { court decisions; state and local regulations }\end{array}$ \\
\hline
\end{tabular}


India's affirmative action is referred to as compensatory discrimination in that its primary goal, at least at inception, was to compensate affected castes for subjection to past discrimination and oppression (Prior, 1996). This constitutionally mandated system of compensatory discrimination provided prohibitions against discrimination based on religion, race, caste, sex, and place of birth.

\section{Theoretical foundation}

\subsection{Structure of $A A P$}

Affirmative action has been presented over many decades as a useful means for adjusting the abuse and repression of individual and group civil rights. Business organizations view affirmative action as a results oriented effort to have the work environment reflect the demographics of the recruitment areas from which they draw employees (Crosby \& VanDeVeer, 2000). In businesses, affirmative action implementation is a component of human resource planning that gives rise to a strategic focus in improving individual and organizational performance.

The structure of the AAP reflects how different components of an AAP are operationalized and implemented. Existing research has conceptualized three types of AAP structures-basic elimination of discrimination, opportunity enhancement, and preferential treatment (Kravitz et al., 1995; Kravitz \& Klineberg, 2002). Basic elimination of discrimination plans involves special efforts by firms to remove all forms of race- and gender-based discrimination. Opportunity enhancement plans involve efforts to get qualified women and racial/ethnic minorities to apply, or to hire racial/ethnic minorities or women when their qualifications are equal to those of whites and men. Preferential treatment structure involves the hiring of less qualified minorities and women over more qualified non-minorities and men. The structure of AAPs and their corresponding implementation strategies significantly affect attitudes towards affirmative action and beneficiaries of affirmative action (Kravitz \& Klineberg, 2002).

In the present study, we used two structures of AAPs to examine perceptions of American and Indian employees, namely, opportunity enhancement and preferential treatment. We conceptualize preferential treatment structure as a "strong" affirmative action strategy where quotas are used and persons are hired mainly due to their race, gender, and caste or class background. Conversely, we conceptualize opportunity enhancement structure as a weak affirmative action policy that does not require quotas or lowering of standards. In opportunity enhancement AAPs, firms proactively seek and promote racial/ethnic minorities and women.

Our choice of the two AAP structures is guided by their relevance to the differences in AAP implementation in India and the United States. Basic elimination of discrimination lies at the core of AAPs in both countries. However, the two countries differ in their operationalizations of affirmative action. India has a more "strong" AAP that is mandatory and requires quotas, which leans more towards the preferential treatment structure. On the other hand, AAPs in the United States are generally voluntary and mainly emphasize seeking out qualified individuals from targeted groups and encouraging their employment. Thus, AAPs in the United States lean more towards the opportunity enhancement structure. These differences in the structure of AAPs between the two countries have major implications for the differences in attitudes towards AAPs in these countries. Several studies suggest that the resistance to affirmative action due to perceptions of fairness (procedural justice) and equality (distributive justice) is linked to the structure of AAPs (Ozawa et al., 1996). Thus, we expect Indian and American employees to have different attitudes towards AAPs.

Extant research suggests that attitude towards AAPs is affected by the structures of the plan itself (Klineberg \& Kravitz, 2003; Taylor-Carter, Doverspike, \& Cook, 1995). Most studies have found that people prefer opportunity enhancement AAPs rather than preferential treatment AAPs for two reasons: compromise of merit and fairness. Merit-based decisions are preferred to any type of preferential treatment (Heilman, McCullough, \& Gilbert, 1996). Negative reactions to preferential treatment result from perceptions that such practices violate principles of meritocracy and individual achievement by lowering standards through forced hiring of marginal and lesser qualified individuals (Crosby \& VanDeVeer, 2000; Guerrero, 2002; Heilman et al., 1996). Prefer- 
ential treatment AAPs also draw negative reactions because employees believe that quotas and reservations deny qualified individuals opportunities and that such compromise of merit promotes inefficiency in firms (Jain et al., 2003; Prior, 1996). Compromise of merit is seen as a lesser problem in opportunity enhancement AAPs.

Researchers contend that attitudes towards AAPs are also driven by fairness judgments. Opportunity enhancement AAPs are considered higher on fairness than preferential treatment AAPs. In the United States, Nacoste (1987) found that negative reactions to preferential AAPs were a result of subjects' perception that the organization is not committed to fairness. Similarly, Kravitz and Van Epps (1995) found that explanations of adverse reactions to preferential treatment AAPs were likely to include negative perceptions of procedural fairness and equal opportunity. In India, the notion of fairness rests more in the "creamery effect" that is tied to the socio-economic status of the beneficiaries of AAPs. One of the criticisms of preferential treatment AAPs in India is that they mainly target individuals with high socio-economic status who do not need aid, but enjoy the rewards of AAPs (Jain et al., 2003; Prior, 1996). Thus, employees in both countries are likely to be more favorable towards opportunity enhancement AAPs than preferential treatment AAPs.

Research question 1: Will employees in both India and the United States have more favorable attitude towards opportunity enhancement AAPs than preferential treatment AAPs?

The primary concern that drives research on the effect of affirmative action on beneficiaries is doubt of qualification for employment or promotion that is directed towards beneficiaries by co-workers. Negative perceptions of beneficiaries include lack of motivation, unqualified to perform, lack of skill, inadequate education and the need for more training. Positive perceptions include comments such as the beneficiary is competent, and is an excellent hire (Taylor-Carter et al., 1995). Existing research on affirmative action suggests that perceptions of beneficiaries of preferential treatment AAPs are less favorable than for the beneficiaries of opportunity enhancement AAPs (Taylor-Carter et al., 1995). Preferential treatment AAPs characterized by forced hiring or perceived quotas result in the most negative perceptions of beneficiaries (Crosby \& VanDeVeer, 2000; Heilman, Block, \& Stathatos, 1997). On the other hand, opportunity enhancement AAPs reflecting opportunity enhancement elements result in more favorable perceptions of beneficiaries (Kravitz et al., 1995). Thus, perceptions of beneficiaries are likely to be less favorable among Indian employees than the American employees based on the structure of AAPs in the two countries.

Research question 2: Will employees in both India and the United States have more favorable attitude towards beneficiaries of opportunity enhancement AAPs than beneficiaries of preferential treatment AAPs?

\subsection{Cultural differences}

A country's culture shapes the norms, beliefs and values of individuals working in organizations (Hofstede, 1980; Singh, 1990; Triandis, 1995). Recent studies on AAPs suggest that differences in cultural beliefs including morals, customs and habits between countries have major implications for the way employees perceive, react to and accept affirmative action policies (Ozawa et al., 1996). Indian and American cultures differ in two major areas most relevant to AAPs: individualism and pluralism.

Individualism reflects the relationship between the individual and the collectivity which prevails in a given society and is demonstrated in the way people live together, e.g. in nuclear families, extended families or tribes (Hofstede, 1980; Hofstede \& Peterson, 2000). American culture is characterized by high individualism with loosely knit social frameworks. In individualistic societies, people are supposed to take care of themselves and their immediate families. On the other hand, collectivism implies a tight social framework in which people expect their social groups to look after them and in return they owe their loyalty to their group (Hofstede, 1980). Empirical studies have found Indian managers to be low on individualism compared to the managers in the United States (Hofstede, 1980; Singh, 1990; Sinha, et al., 2002). Indian managers are embedded in groups based on family, ethnic background, kinship and language (Sinha \& Sinha, 1990). 
Individualism is found to affect employees' attitude towards management practices in general as well as AAPs in particular. Since individualism is high in the United States (Hofstede, 1980; Robert et al., 2000; Singh, 1990, Sinha et al., 2002; Triandis, 1995), work and accomplishments are viewed as person centered (Triandis \& Gelfand, 1998). However, the collectivistic culture in India promotes collective embeddedness with loyalty and collective norms being paramount (Singh, 1990). Collective achievements and well-being are as important as or even more important than individual merit in such cultures. For example, Robert et al. (2000) found that individual centered empowerment practices were perceived negatively by Indian employees, but positively by American employees. Thus, issues of individual meritocracy and perceptions of fairness are likely to be more pronounced among American employees than Indian employees. Specifically, perceptions of compromise of individual merit and fairness in implementing AAPs are likely to be higher among American employees than Indian employees. Since AAPs aim at building a more balanced and diverse collective workforce, we expect the collective Indian culture to be more favorable towards AAPs. The relationship between individualism and attitudes towards AAPs has also been empirically demonstrated. Ozawa et al. (1996) found that subjects in a collectivist culture (Japan) were more favorable to AAPs than the subjects in an individualistic culture (United States). Thus, we expect Indian employees to have more favorable attitudes towards AAPs than American employees.

Pluralism refers to the degree to which national culture fosters simultaneous coexistence of different ethnic groups with strong identities (Brass, 1991; Miller, 1995, Mitra, 1999; Parekh, 1991). In a low pluralism culture, minority groups are completely absorbed by the dominant culture. The minority groups either completely replace their identities with those of the dominant culture, or retain weaker cultural linkages with the dominant cultural group. High pluralism on the other hand characterizes simultaneous coexistence of diverse ethnic groups with strong identities. Indian culture embodies pluralism where seemingly contradicting thoughts and actions instead of leading to confrontations and to some kind of resolution, are tolerated, balanced, accommodated or just allowed to exist (Mitra, 1999; Parekh, 1991). In contrast, American culture is non- pluralistic where cultural differences are unified into a coherent, universal work culture (Brass, 1991; Mitra, 1999). Diverse groups are absorbed into the mainstream work culture to create uniform work norms, beliefs and values.

We argue that the degree of cultural pluralism may also affect attitudes towards AAPs. However, the relationship between pluralism and attitude towards AAPs is quite tenuous. On the one hand, pluralistic cultures, such as India, are likely to be less offended by affirmative action than non-pluralistic cultures that favor a unified society. This is because high pluralism embeds tolerance of conflicts and contradictions among diverse ethnic groups (Brass, 1991; Mitra, 1999; Singh, 1990). Pluralistic culture, that accommodates coexistence of distinct groups (India), is likely to be more tolerant of the diversity fostered by AAPs than a non-pluralistic society that favors a unified dominant work culture (United States).

On the other hand, pluralistic cultures can also lead to negative attitudes towards AAPs because of the ingroup-out-group ideology. Non-pluralistic cultures focus on smooth integration of diverse cultures into a coherent culture. In such a non-pluralistic culture, minority communities have weak identities and legitimacy. Thus, the in-group-out-group ideology may not be as prominent in non-pluralistic cultures as in pluralistic culture. Rather than compete with minority cultures, the dominant culture aims at absorbing the minority cultures (Brass, 1991; Mitra, 1999; Singh, 1990). However, in pluralistic cultures such as India, minority groups enjoy more legitimacy and have stronger identities. Thus, the in-group-out-group ideology is likely to be more prominent in India than in the United States. This suggests that non-beneficiaries in the Unites States will feel less threatened by the AAPs than their counterparts in India. This literature on the structure of AAP and national culture led us to pose the following questions:

Research question 3: What are the differences in the attitudes towards AAPs between employees in India and the United States?

Research question 4: Will the differences between attitudes towards opportunity enhancement AAPs and preferential treatment AAPs differ between employees in India and the United States? 
Cross-national studies of AAPs suggest that collectivist cultures have more positive perceptions of beneficiaries than individualistic cultures (Ozawa et al., 1996). This is because perceptions of unfairness and compromise of merit are more prominent in individualistic cultures than collectivist cultures. This implies that American employees will have less favorable perceptions of beneficiaries than Indian employees. Moreover, the tolerance of pluralism and contradiction embedded in the pluralistic culture of India is likely to lead to more positive perceptions of beneficiaries. At the same time, the in-group-outgroup ideology resulting from pluralism (Brass, 1991; Mitra, 1999) is likely to lead to more negative perceptions of beneficiaries among the Indian employees than the American employees. The above discussion frames the following research question.

Research question 5: What are differences in the perceptions of beneficiaries between employees in India and the United States?

\subsection{Sample}

Three criteria guided our sampling strategy. First, we chose firms that were directly impacted by the AAPs in India and the United States. Second, differences in the perceptions of AAPs due to cultural differences may be more pronounced for newly internationalized or non-internationalized firms rather than established MNCs, where exchange of information and knowledge from different countries may dilute country-specific perceptions (Bartlett \& Ghoshal, 1989). Finally, we chose comparable agencies (governmental), engaged in similar industries (insurance). To fulfill these criteria, we selected two governmental insurance agencies, one each in India and the United States. The national insurance agency in India was covered by the AAP and was required to meet the reservation quotas in recruitment. Although, the state insurance agency in the United States was not required to meet specific quotas, it was required by state law to submit an AAP and encouraged to develop timetables and goals for recruiting and promoting minority and women candidates. The insurance agency in India was engaged in international operations for two years, whereas the agency in the United States was in the process of undertaking international transactions. We sampled subjects who worked in the administrative units of each agency. The subjects in both of the agencies had broad duties and responsibilities such as agency accounting, payroll, and employee relations.

We received completed responses from 80 subjects in India (response rate $70 \%$ ) and 77 subjects from United States (response rate 79\%). Of the 157 participants, $42.02 \%$ were men and $47.98 \%$ were women; $16.2 \%$ were managers, $16.9 \%$ were supervisors, and $60.8 \%$ were staff. For the American sample, $7 \%$ of the subjects belonged to the racial/ethnic minorities that are targeted by AAPs in the United States, and $93 \%$ were white. For the Indian sample, $11 \%$ were from reserved (SC/ST/OBC) classes that are targeted by AAPs in India, and 89\% were from non-reserved groups.

\subsection{Data collection}

We used the survey method to collect data. We designed a survey to specifically capture respondents' attitudes towards affirmative action. We distributed the surveys to voluntary participants during work time, with two weeks for completion. Participants were assured anonymity and were provided with addressed return envelops at the time of survey distribution to return their responses to principal researchers. To enhance the reliability of the survey items, we pilot tested our survey using 22 Americans and 25 Indians who were not a part of the final sample. We asked them if they had any problems understanding the items or if they found the items unclear and vague. None of the pilot subjects had any major problems with the descriptors.

\subsection{Measures}

\subsubsection{Cultural variables}

We used six items from Triandis (1995) Likert type (strongly agree-disagree) scale of individualism and collectivism (coefficient $a=0.66$ ). The scale included items such as "What happens to me is my own doing" and "I feel good when I cooperate with others". The Indian managers had significantly higher collectivism ratings than the American managers $(F=75.42$; $p<0.0001)$.

We developed a four-item seven-point Likert scale (strongly agree-disagree) of pluralism by adapting previous measures (Brass, 1991; Mitra, 1999) to our study through extensive pilot tests. Modifications 
to the original scales were based on face validity in terms their relevance to affirmative action and their meaningfulness to subjects. The scale included statements such as "Every ethnic community should be allowed to have its own laws to govern marriage and property right" and "Contradictions and conflicts among different ethnic communities should be allowed to exist and not resolved". The four items yielded a single factor (eigenvalue: 2.91; variance explained: 0.73). Hence, we used a composite measure of pluralism by averaging the $z$-scores of the individual items (coefficient $a=0.87$ ). The pluralism ratings of Indian managers were significantly higher than the American managers $(F=111.44 ; p<0.0001)$.

\subsubsection{Attitude towards AAPs}

Consistent with prior research, we measured attitudes towards opportunity enhancement and preferential treatment by providing the subjects with two different AAP situations (Kravitz \& Klineberg, 2002; Taylor-Carter et al., 1995). Situation 1 (preferential treatment) describes a hard/strong AAP that is based on specific numerical quotas set for targeted groups and is mandatory. Situation 2 (opportunity enhancement) outlines a weak/soft AAP that does not require quotas or lowering standards and is not mandatory. Rather, the goal of the AAP is to hire and promote underprivileged groups who are qualified to do the work. We developed a manipulation check to check whether the respondents perceived the two situations as preferential treatment and opportunity enhancement. The ratings of preferential treatment for situation 1 (preferential treatment) were significantly higher than situation 2 (opportunity enhancement) $(F=4.65 ; p<0.05)$, which confirms the validity of the two AAP manipulations.

We used three items to measure subjects' attitudes towards AAPs in each situation: the degree to which they favored/opposed the AAP for underprivileged groups and women, the degree to which they thought the AAP was needed in their respective country, and the degree to which they found the AAP should be increased, decreased or kept the same (Kravitz et al., 1995). The coefficient $a$ for the three items was 0.94 for preferential treatment and 0.89 for opportunity enhancement.

Also, based on extant research, we provide six descriptors of problems associated with AAPs in India (Alexander \& Jacobsen, 1999; De Zwart, 2000; Tum- mula, 1999) and the United States (Crosby \& VanDeVeer, 2000; Guerrero, 2002; Heilman et al., 1997): strict quotas are required; enough has already been done to improve the status of affirmative action groups; affirmative action works against a system of merit; those who benefit do not deserve special treatment; those who benefit are not the ones who need it; and discrimination against racial/ethnic minorities, women and backwards classes no longer exists.

\subsubsection{Perceptions of beneficiaries of AAPs}

We asked the subjects to identify how persons hired under affirmative action are generally perceived. We gave the subjects three positive descriptors (competent to do the work, a good addition to the organization and has the necessary education) and four negative descriptors (unqualified to do work, require more training, lack the needed education and should not have been hired) identified by prior research (Crosby \& VanDeVeer, 2000; Guerrero, 2002, Heilman et al., 1996, Kravitz et al., 1995; Turner, 1990).

\subsubsection{Control variables}

We used six control variables: age, gender, ethnic background (minority/non-minority), education, racial attitude and job position (staff/supervisor/manager). Younger subjects may have a more favorable attitude towards AAPs than older subjects (Kravitz et al., 1995), whereas females are more favorable towards AAPs than males (Ozawa et al., 1996; Singer, 1993). Studies have found that ethnic minority subjects are more favorable towards affirmative actions than non-minority subjects (Kinder \& Sanders, 1990; Sigelman \& Welch, 1991). Education and job position are also considered correlates of attitudes towards affirmative action (Kravitz et al., 1995). Finally, racial attitude is shown to have a positive relationship with attitude towards AAPs. We measured the racial attitude by a three-item scale developed by Merriman and Parent (1983) that measures the degree of racial prejudice among individuals (coefficient $a=0.70$ ). The scale asks subjects to rate the reasons (ranging from major to minor) why differences between privileged and underprivileged groups exist. Exploratory factor analysis yielded a single factor. To avoid multi-collinearity, we averaged the three items into a composite measure of racial attitude. 


\subsection{Analyses}

We used the paired $t$-test to examine the withincountry differences between attitude towards opportunity enhancement AAPs and preferential treatment AAPs. We used a repeated measures factorial ANOVA to examine if the differences in the attitudes towards preferential treatment and opportunity enhancement AAPs in India are significantly higher than the differences between the two AAPs in the United States. We used MANOVA to investigate the significance of between-country differences in the attitudes towards AAPs. In the MANOVA, the factor was country, coded as India (0) and United States (1). Finally, we used the Chi-square test of independence to examine the differences in each descriptor of beneficiaries of AAPs using a $2 \times 2$ contingency table (descriptor (yes, no) $\times$ country (India, United States)). We used Yates' correction when the frequency in any cell was less than 5 (Siegel \& Castellan, 1988).

\section{Results}

\subsection{Descriptive statistics}

The correlations among study variables are shown in Table 2. None of the demographic variables, except gender, is significantly correlated to attitudes towards either preferential treatment AAPs or opportunity enhancement AAPs. Country has a significant correlation with attitude towards special treatment AAPs $(p<0.01)$, but not with attitude towards opportunity enhancement AAPs. Racial attitude is significantly correlated with attitudes towards preferential treatment AAPs $(p<0.001)$ as well as opportunity enhancement AAPs $(p<0.01)$.

\subsection{Differences in attitudes towards preferential treatment AAPs and opportunity enhancement AAPs}

We conducted a paired samples $t$-test to examine the differences in attitudes towards preferential treatment AAPs and opportunity enhancement AAPs in each country. These results are shown in Table 3 . The results suggest that the attitude towards opportunity enhancement AAPs was significantly more favorable than the attitude towards preferential treatment AAPs in both the Indian $(t=9.00$; $p<0.0001)$ and the American $(t=7.634)$ samples. We further examined if there were between-country differences in the perceptions of the two AAPs using the two-factor (preferential treatment and opportunity enhancement) between-subjects (Indian and United States) repeated measures ANOVA. We used age, education, job position and gender as covariates in the analyses. These results are shown in Table 4. The results suggest that the difference in the attitude towards the two AAPs was significantly higher in the Indian sample than in the American sample $(F=4.497 ; p<0.05)$.

Table 2. Descriptive statistics of and correlations among study variables

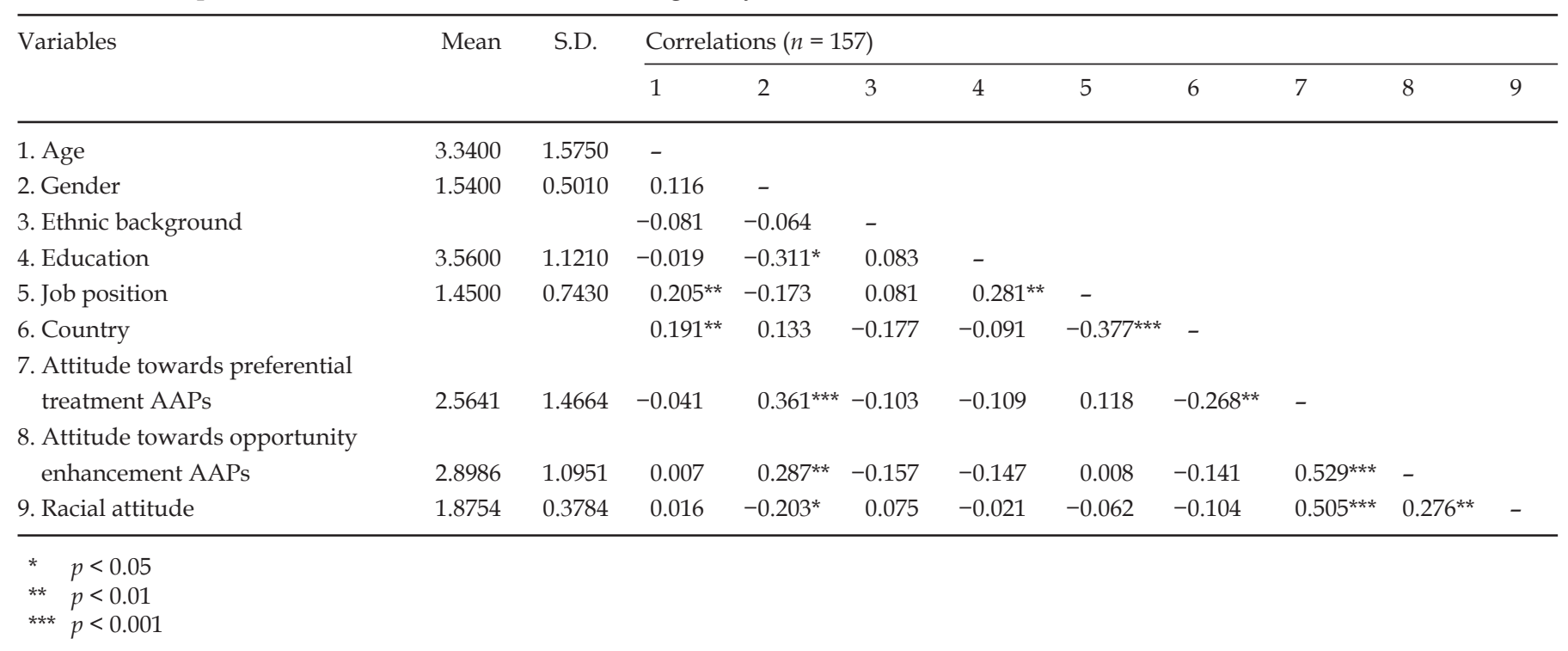


The Chi-square test results of the within-country differences in the positive and negative perceptions towards beneficiaries of preferential and opportunity enhancement AAPs are shown in Table 5. A significantly greater proportion of employees in the Indian as well as American samples found that beneficiaries of preferential treatment AAPs require more training and lack needed education than the beneficiaries of opportunity enhancement AAPs. On the other hand, a greater proportion of employees in the two countries found that beneficiaries of opportunity enhancement affirmative action were competent to do the work, have the necessary education and a good addition to the organization than the beneficiaries of preferential treatment AAPs. Similarly, the proportion of employees in the two countries who chose that beneficiaries of preferential treatment AAPs should not have been hired was higher than the proportion of employees who chose that beneficiaries of opportunity enhancement AAPs should not have been hired.

\subsection{Differences in attitude towards AAPs in India and the United States}

The MANOVA results of the differences in the attitude towards AAPs in India and the United States are shown in Table 6. American employees have a

Table 3. Paired sample $t$-test results of the differences in the attitude towards preferential treatment AAPs and opportunity enhancement AAPs in India and the United States

\begin{tabular}{lccc}
\hline Country & $t$ & Mean preferential treatment AAPs & Mean opportunity enhancement AAPs \\
\hline India $(n=80)$ & $9.005^{* * *}$ & 3.074 & 4.657 \\
United States $(n=77)$ & $7.634^{* * *}$ & 3.123 & 4.206 \\
\hline
\end{tabular}

$* * * \quad p<0.001$

Table 4. Comparison of differences in preferential treatment AAPs and opportunity enhancement AAPs between India and the United States

\begin{tabular}{|c|c|c|c|c|}
\hline \multicolumn{5}{|r|}{$\begin{array}{l}\text { es in preferential treatment } \\
\text { y enhancement }\end{array}$} \\
\hline Variable & Value & $F$ & India & United States \\
\hline Pillai-Bartlett trace & 0.038 & $4.497^{*}$ & & \\
\hline Hotellings trace & 0.039 & $4.497^{*}$ & & \\
\hline
\end{tabular}

$* p<0.05$

Table 5. Chi-square results of differences in the perceptions of beneficiaries of preferential treatment and opportunity enhancement AAPs in India and the United States

\begin{tabular}{|c|c|c|c|c|c|c|c|c|}
\hline \multirow[t]{2}{*}{ Perceptions of beneficiaries of AA } & \multicolumn{4}{|l|}{ India } & \multicolumn{4}{|l|}{ United States } \\
\hline & $\begin{array}{l}\text { Preferential } \\
\text { treatment } \\
\text { (\% of subjects, } \\
n=80 \text { ) }\end{array}$ & $\begin{array}{l}\text { Opportunity } \\
\text { enhancement } \\
\text { (\% of subjects, } \\
n=80 \text { ) }\end{array}$ & $\begin{array}{l}\text { Chi- } \\
\text { square }\end{array}$ & $p$-value & $\begin{array}{l}\text { Preferential } \\
\text { treatment } \\
\text { (\% of subjects, } \\
n=77 \text { ) }\end{array}$ & $\begin{array}{l}\text { Opportunity } \\
\text { enhancement } \\
\text { (\% of subjects, } \\
n=77 \text { ) }\end{array}$ & $\begin{array}{l}\text { Chi- } \\
\text { square }\end{array}$ & $p$-value \\
\hline 1. Unqualified to do work & 57 & 23 & 14.45 & 0.0001 & 49 & 38 & 6.89 & 0.009 \\
\hline 2. Competent to do the work & 31 & 49 & 4.05 & 0.04 & 27 & 48 & 4.83 & 0.028 \\
\hline 3. Require more training & 45 & 25 & 5.71 & 0.016 & 32 & 14 & 7.043 & 0.008 \\
\hline 4. A good addition to organization & 17 & 31 & 4.083 & 0.04 & 31 & 48 & 3.282 & 0.05 \\
\hline 5. Lack the needed education & 49 & 27 & 6.368 & 0.011 & 37 & 22 & 3.814 & 0.05 \\
\hline 6. Has the necessary education & 22 & 36 & 3.379 & 0.066 & 26 & 43 & 4.188 & 0.04 \\
\hline 7. Should not have been hired & 48 & 31 & 3.2 & 0.074 & 63 & 44 & 4.4 & 0.036 \\
\hline
\end{tabular}


significantly more favorable attitude towards preferential treatment AAPs than the Indian employees $(F=4.061 ; p<0.01)$. However, there are no significant differences in the attitude towards opportunity enhancement AAPs between the two countries.

We further examined the differences in the perceptions of problems associated with AAPs in the two countries using the Chi-square test. The Chi-square test results of the differences in the problems with AAP identified by the Indian and American employees are shown in Table 7. The proportion of Indian employees who identified the problem with AAPs was significantly higher for all descriptors except strict quotas are required.

The Chi-square test results of the differences in the positive and negative perceptions towards beneficiaries of affirmative action in the Indian and American samples are shown in Table 8. There are differences in the positive as well as negative perceptions towards beneficiaries in the American and Indian samples. A significantly greater proportion of Indian employees found that beneficiaries of affirmative action require

Table 6. MANOVA of attitude towards AAPs by country

\begin{tabular}{|c|c|c|c|c|c|c|}
\hline \multicolumn{3}{|l|}{ MANOVA $n=157$} & \multicolumn{4}{|l|}{ Univariate ANOVA $(n=157)$} \\
\hline Variable & Value & $F$ & Variable & $F$ & Mean India & Mean United States \\
\hline Wilks' lambda & 0.653 & $3.434^{* * *}$ & $\begin{array}{l}\text { Attitude towards preferential } \\
\text { treatment AAPs }\end{array}$ & $4.061^{*}$ & 1.37 & 1.91 \\
\hline Pillai-Bartlett trace & e 0.347 & $3.434^{* * *}$ & $\begin{array}{l}\text { Attitude towards opportunity } \\
\text { enhancement AAPs }{ }^{\text {a }}\end{array}$ & 0.08 & 1.85 & 1.74 \\
\hline
\end{tabular}

a. The higher the rating, the more positive the attitude towards AAPs.

* $\quad p<0.05$

$* * * \quad p<0.001$

Table 7. Chi-square results of differences in problems with AAP identified by Indian and United States workers

\begin{tabular}{|c|c|c|c|c|}
\hline Problems with AAP & $\begin{array}{l}\% \text { of subjects } \\
\text { in India } \\
(n=80)\end{array}$ & $\begin{array}{c}\% \text { of subjects } \\
\text { in the U.S. } \\
(n=77)\end{array}$ & Chi-square & $p$-value \\
\hline 2. Enough has already been done to improve the status of AA groups & 0.426 & 0.159 & 10.757 & 0.001 \\
\hline 3. I believe that AA works against a system of merit & 0.815 & 0.638 & 4.669 & 0.031 \\
\hline 6. Discrimination against women and backwards classes no longer exists & 0.166 & 0.0299 & 7.052 & 0.008 \\
\hline
\end{tabular}

Table 8. Chi-square results of differences in the perceptions of beneficiaries of AA between Indian and United States workers

\begin{tabular}{lcccc}
\hline Perceptions of beneficiaries of AAPs & $\begin{array}{c}\text { \% of subjects } \\
\text { in India } \\
(n=69)\end{array}$ & $\begin{array}{c}\text { \% of subjects } \\
\text { in the U.S. } \\
(n=69)\end{array}$ & Chi-square & $p$-value \\
\hline 1. Unqualified to do work & 0.130 & 0.203 & 1.149 & 0.284 \\
2. Competent to do the work & 0.130 & 0.246 & 2.629 & 0.104 \\
3. Require more training & 0.537 & 0.145 & 21.509 & 0.0000 \\
4. A good addition to organization & 0.000 & 0.173 & 6.116 & 0.013 \\
5. Lack the needed education & 0.333 & 0.855 & 8.668 & 0.003 \\
6. Has the necessary education & 0.0370 & 0.116 & 2.525 & 0.112 \\
7. Should not have been hired & 0.0357 & 0.145 & 4.249 & 0.039 \\
\hline
\end{tabular}


more training and lack needed education than the American employees. On the other hand, a greater proportion of American employees found that beneficiaries of affirmative action were a good addition to the organization. However, the proportion of American employees who chose that beneficiaries of affirmative action should not have been hired was higher than the proportion of Indian employees. Finally, there were no significant differences in the proportions of employees in the Indian and American samples who found that the beneficiaries of affirmative action were competent to do the work and have the necessary education.

\section{Discussion}

Effectively managing diversity and coordinating policies are critical to the success of MNCs in both the United States and India. With the intention to fill a void in existing literature on AAPs, the current study explored the cross-country and cross-cultural influences on attitude towards AAPs that may inform MNCs as they manage the integration of domestic and international affirmative action policies and strategies. There are three major results of this study. First, both Indian and American employees preferred the opportunity enhancement AAPs to preferential treatment AAPs. Second, the difference between preferential treatment AAPs and opportunity enhancement AAPs was higher among the Indian employees than the American employees. Finally, the attitude towards beneficiaries was less favorable among the Indian employees than the American employees. These results have some interesting implications.

Our results of the within-country analyses suggest that both American and Indian employees preferred opportunity enhancement AAPs to preferential treatment AAPs. This supports previous literature that has found more positive attitudes towards opportunity enhancement AAPs than preferential treatment AAPs (Heilman et al., 1996). Preferential treatment AAPs may have evoked higher perceptions of compromise of individual merit and fairness than opportunity enhancement AAPs among employees in India as well as in the United States. For example, significantly more Americans and Indians found that beneficiaries of preferential treatment AAPs lacked the competence and education needed to do the work than those who found lack of competence and education among beneficiaries of opportunity enhancement AAPs.

Indian employees may also have preferred opportunity enhancement AAPs to preferential treatment AAPs because of the creamery effect. Preferential treatment AAPs in India are considered unfair because they mainly target individuals with high socioeconomic status who do not need aid, but enjoy the rewards of AAPs (Jain et al., 2003 and Prior, 1996). Since opportunity enhancement AAPs represent a conscious effort to actively seek underprivileged individuals who exhibit job related credentials, perceptions of unfairness may have been relatively less among Indian employees.

Our between-country findings differ from those of cross-national studies that found that individuals from collectivist cultures were more favorable towards AAPs than individuals from individualistic cultures (Ozawa et al., 1996). The prevalence of in-group-out-group ideology fostered by pluralism may explain why Indian employees were less favorable towards AAPs than American employees. This possibility is especially relevant to our study since our Indian sample consisted mainly of non-beneficiaries $(89 \%)$ who may find their collective self interest threatened by AAPs that provide privileges to selective 'other' communities. This in-group-outgroup ideology is evident in the history of AAP implementation in India (Jain et al., 2003; Prior, 1996). The implementation of a mandatory AAP, with specific quotas for targeted groups in higher education and employment agencies by the Mandal Commission in 1980, was fiercely opposed by the students as well as working classes who did not belong to targeted groups.

An interesting result of this study is the difference in the problems associated with AAPs in India and the United States. In the Indian sample, we found support for the perceptions of "creaming effect". A significantly greater proportion of Indian employees identified creaming as a problem associated with AAPs than the U.S. employees. The resistance to AAPs due to the creaming effect has been identified by prior studies (Jain et al., 2003; Prior, 1996). However, the proportion of American employees that emphasized that beneficiaries "should not have been 
hired" was significantly higher than the Indian employees. This suggests that procedural justice may be an important driver of resistance in the Unites States (Taylor-Carter et al., 1995). This is consistent with previous research, which suggests that issues of procedural justice are likely to be more prominent in individualistic cultures (United States) than collectivistic cultures (India) (Ozawa et al., 1996).

Regarding the perceptions of beneficiaries of AAPs, Indian employees had more negative perceptions of beneficiaries than the U.S. employees. This difference between Indian and U.S. employees is consistent with existing literature on pluralism. Pluralism studies suggest that the strong identity and legitimacy of different communities creates tensions that lead to in-group-out-group ideologies in such cultures. Thus, non-beneficiaries in India are likely to perceive beneficiaries more negatively than their counterparts in the United States (Brass, 1991; Mitra, 1999).

\subsection{Limitations}

This study used survey method for data collection. While this was an expedient process given the crosscountry logistics of the study, common methods variance must be considered. While using data from one industry sector strengthened the comparability of samples across country cultures, the generalizability of study results may be hampered. Finally, although we used firms from comparable industries and sampled subjects with comparable duties and responsibilities, we did not perfectly match the two firms. We, therefore, cannot fully rule out the alternative explanations of differences in attitude towards AAPs due to differences in firm-specific work cultures of the two agencies.

\subsection{Practical implications}

For MNCs, it is critical to integrate human resource policies with AAPs from different countries. A first step in coordinating AAPs around the world would be to understand the convergence and divergence in the plan structure as well as employee perceptions of implementation practices. Our study provides interesting insights into the differences in employee's perceptions of AAPs in India and the United States. These differences highlight both the positive and negative attitudes that people have about AAPs in the two countries. MNCs can use these results in initiating strategies to support the implementation of AAPs including, diversity training, recruitment, selection, promotion and developmental opportunities. For example, one of the problems identified by Indian and American employees about affirmative action is the perception that it works against a system of merit. Employers should be aware of this issue and justify employment decisions based on the competencies of the selected candidates and stress that merit is not compromised. Further, the content and structure of diversity training and education programs cannot be superimposed without consideration of country and cultural differences. Such efforts must be specifically tailored for the specific environment, building employee skills to support and address particularistic ideals, issues and concerns.

Proper communications can reduce the unfavorable perceptions that are held towards beneficiaries of AAPs, improving the effectiveness of AAPs. Managers need to consider the differences in the type of information that is provided to non-beneficiaries to make AAPs more acceptable to them. For example, in India the issue of the "creamery effect" might dictate more detailed information about hiring/employment procedures or the fit of individual credentials to the knowledge, ability and skill needs of the job into which they were hired or promoted. When implementing affirmative action, MNCs must develop and articulate a precise and congruent ideological framework for the program. Application of policies and procedures must not only be fair and consistent, but understood within the socio-political context of the particular country. Our study may help MNCs build internal plans to fit the AAP structure of respective countries to maximize the benefits of diversity by fostering a positive work climate.

\section{Acknowledgments}

We thank Michael Combs, Fred Luthans, Gerry Giraud, Mrudula Nadkarni, and Fred Walumbwa for their review and helpful comments on previous versions of this paper. 


\section{References}

Alexander and Jacobsen, 1999 A. Alexander and K. Jacobsen, Affirmative action: A critical reconnaissance, International Journal of $U r-$ ban \& Regional Research 22 (1999) (3), pp. 593-600.

Bartlett and Ghoshal, 1989 ४ C. Bartlett and S. Ghoshal, Managing across Borders, HBS Press, Cambridge, MA (1989).

Boston and Nair-Reichert, $2003 \triangleleft$ T. Boston and U. Nair-Reichert, Affirmative action: Perspectives from the United States, India and Brazil, The Western Journal of Black Studies 27 (2003), pp. 3-14.

Brass, $1991 \triangleleft$ P. R. Brass, Ethnicity and Nationalism: Theory and Comparison, Sage, New Delhi (1991).

Crosby and VanDeVeer, $2000<$ F. J. Crosby and D. VanDeVeer, Sex, Race, and Merit: Debating affirmative Action in Education and Employment, University of Michigan Press, Ann Arbor, MI (2000).

De Zwart, 20004 F. De Zwart, The logic of affirmative action: Caste, class and quotas in India, Acta Sociologica 43 (2000), pp. 235-250.

Evan et al., 20024 P. Evan, V. Pucik, and J. Barsoux, The Global Challenge: Frameworks for International Human Resource Management, McGraw-Hill/Irwin, New York, NY (2002).

Guerrero, 20024 A. Guerrero, Affirmative Action in Perspective: Silence at Boalt Ball-The Dismantling of Affirmative Action, University of California Press, Berkeley, CA (2002).

Heilman et al., 19974 M. E. Heilman, C. J. Block, and P. Stathatos, The affirmative action stigma of incompetence: Effects of performance information ambiguity, Academy of Management Journal 40 (1997), pp. 603-625.

Heilman et al., 19964 M. E. Heilman, W. F. McCullough, and D. Gilbert, The other side of affirmative action: Reactions of non-beneficiaries to sex-based preferential selection, Journal of Applied Psychology 81 (1996), pp. 346-357.

Hofstede, $1980<$ G. Hofstede, Culture's Consequences, Sage, Beverly Hills, CA (1980).

Hofstede and Peterson, $2000<$ G. Hofstede and M. F. Peterson, Culture: National values and organizational practices. In: N. M. Ashkanasy, C. P. M. Wilderon and M. F. Peterson, Editors, Handbook of Organizational Culture and Climate, Sage, Thousand Oaks, CA (2000), pp. 401-415.

Iles and Hayers, $1997 \varangle$ P. Iles and P. K. Hayers, Managing diversity in transnational project teams, Journal of Managerial Psychology $\mathbf{1 2}$ (1997), pp. 95-117.

Jain et al., $2003 \triangleleft$ H. C. Jain, P. J. Sloane, and F. M. Horwitz, Employment Equity and Affirmative Action, M. E. Sharpe, New York, NY (2003).

Kinder and Sanders, $1990<$ D. R. Kinder and L. M. Sanders, Mimicking political debate with survey questions: The case of white opinion on affirmative action for blacks, Social Cognition 8 (1990), pp. 73-103.

Klineberg and Kravitz, 20034 S. L. Klineberg and D. A. Kravitz, Ethnic differences in predictors of support for municipal affirmative action contracting, Social Science Quarterly 84 (2003) (2), pp. $425-440$.

Kravitz, $1995 \varangle$ D. A. Kravitz, Attitudes toward affirmative action plans directed at blacks: Effects of plan and individual differences, Journal of Applied Social Psychology 24 (1995), pp. 2192-2220.

Kravitz et al., $1995<$ D. A. Kravitz, D. A. Harrison, M. E. Turner, E. L. Levine, W. Chaves, M. T. Brannick, et al. Affirmative action: A review of psychological and behavioral research, Society for Industrial and Organizational Psychology Inc., Bowling Green, OH (1995).

Kravitz and Klineberg, 20024 D. A. Kravitz and S. L. Klineberg, Affirmative action attitudes: Effects of respondent ethnicity, AAP strength, and anticipated impacts. In Academy of Management Proceedings, Denver, Colorado (2002).
Kravitz and Van Epps, 1995 D. A. Kravitz and K. Van Epps, Affirmative action and fairness. In F. Crosby (Chair), Concepts of affirmative action. Symposium conducted at the Fifth International Conference on Social Justice Research, Reno, NV (1995, June).

Merriman and Parent, $1983<$ R. Merriman and T. W. Parent, Sources of citizen attitude toward government race policy: A theoretical and empirical exploration, Polity 16 (1983), pp. 30-45.

Miller, 19954 D. Miller, On Nationality, Clarendon Press, Oxford, UK (1995).

Mitra, 1999 S. K. Mitra, Culture and Rationality, Sage, New Delhi (1999).

Nacoste, 19874 R. W. Nacoste, But do they care about fairness?: The dynamics of preferential treatment and minority interest, Basic and Applied Social Psychology 8 (1987), pp. 177-191.

Ozawa et al., $1996 \varangle \mathrm{K}$. Ozawa, M. Crosby, and S. Crosby, Individualism and resistance to affirmative action: A comparison of Japanese and American samples, Journal of Applied Social Psychology 26 (1996), pp. 1138-1153.

Parekh, 1991 B. Parekh, Britain and the social logic of pluralism. In: G. Andrews, Editor, Citizenship, Lawrence and Wishart, London (1991).

Prior, 19964 E. Prior, Constitutional fairness or fraud on the constitution?: Compensatory discrimination in India, Case Western Reserve Journal of International Law 28 (1996), pp. 63-100.

Robert et al., $2000 \varangle$ C. Robert, T. Probst, J. Martocchio, F. Drasgow, and J. J. Lawler, Empowerment and continuous improvement in the United States, Mexico, Poland, and India: predicting fit on the basis of the dimensions of power distance and individualism, Journal of Applied Psychology 85 (2000) (5), pp. 643-658.

Siegel and Castellan, $1988<$ S. Siegel and J. N. Castellan, Nonparametric Statistics, McGraw-Hill, New York, NY (1988).

Sigelman and Welch, 1991 L. Sigelman and F. Welch, Black American's Views of Racial Inequality, Cambridge University Press, Cambridge, MA (1991).

Singer, $1993-$ M. S. Singer, Gender-based preferential selection: Perceptions of injustice and empathy of deprivation, International Journal of Selection and Assessment 1 (1993), pp. 184-202.

Singh, 19904 J. P. Singh, Managerial culture and work related values in India, Organization Studies 11 (1990), pp. 075-101.

Sinha and Sinha, $1990 \varangle$ B. P. Sinha and D. Sinha, Role of social values in Indian organizations, International Journal of Psychology 25 (1990), pp. 705-714.

Sinha et al., 20024 J. B. Sinha, N. Vohra, S. Singhal, R. B. Sinha, and S. Ushashree, Normative predictions of collectivist-individualist intentions and behavior of Indians, International Journal of Psychology 37 (2002), pp. 309-320.

Taylor-Carter et al., $1995 \varangle$ M. A. Taylor-Carter, D. Doverspike, and K. Cook, Understanding resistance to sex and race-based affirmative action: A review of research findings, Human Resource Management Review 5 (1995), pp. 129-157.

Triandis, 1995 H. C. Triandis, Individualism \& Collectivism, Westview Press, Boulder, CO (1995).

Triandis and Gelfand, $1998 \triangleleft$ H. C. Triandis and M. J. Gelfand, Converging measurement of horizontal and vertical individualism and collectivism, Journal of Personality \& Social Psychology 74 (1998) (1), pp. 118-128.

Tummula, $1999 \varangle$ K. K. Tummula, Policy of preference: Lessons from India, the United States, and South Africa, Public Administration Review 59 (1999), pp. 495-509.

Turner, $1990 \triangleleft \mathrm{R}$. Turner, The Origins, Relevant Theories, and Evolution of the Concept of Affirmative Action: The Past and Future of Affirmative Action: A Guide and Analysis for Human Resource Professionals and Corporate Counsel, Quorum Books, New York, NY (1990). 